\title{
Clinical features and treatment with botulinum toxin in blepharospasm: a 17-year experience
}

\author{
Característica clínicas e tratamento com toxina botulínica em blefaroespasmo: \\ experiência de 17 anos \\ Camila Catherine Aquino', Andre C. Felício², Pollyanna Celso Felipe de Castro', Ricardo Araujo Oliveira', \\ Sonia Maria Cesar Azevedo Silva², Vanderci Borges², Henrique Ballalai Ferraz²
}

\begin{abstract}
Objective: It was to analyze clinical aspects of patients with blepharospasm, including outcomes of botulinum toxin treatment. Additionally, clinical characteristics of isolated blepharospasm were compared to those of blepharospasm plus other movement disorders. Methods: Clinical data recorded during 17 years were reviewed. The variables included age, gender, age of onset, past medical history, head trauma, smoking history, family history of dystonia, severity, duration of botulinum toxin relief and adverse effects. Results: A total of 125 patients were included and $75.2 \%$ were female. The mean age of onset was 54.3 years; $89.6 \%$ of the individuals started with contractions in eye region, and $39.2 \%$ of them spread to lower face or neck. Isolated blepharospasm group was compared with blepharospasm-plus group for demographic and clinical features, and therapeutic outcomes, without significant differences. Botulinum toxin treatment improved the severity of contractions ( $p=0.01$ ) with low rate of side effects (14\%). Conclusions: Both groups — isolated blepharospasm and blepharospasm-plus shared similar results concerning epidemiology, clinical features and therapeutic response to botulinum toxin.
\end{abstract}

Key words: blepharospasm, botulinum toxins.

\section{RESUMO}

Objetivos: Analisar as características clínicas de pacientes com blefaroespasmo e os resultados do tratamento com toxina botulínica. Além disso, os pacientes foram divididos em dois grupos, blefaroespasmo isolado e blefaroespasmo associado a outros distúrbios do movimento, os quais foram comparados quanto a características clínicas e terapêuticas. Métodos: Foram revisados prontuários dos últimos 17 anos. As variáveis consideradas foram idade, sexo, idade de início dos sintomas, antecedentes pessoais, história prévia de trauma crânio-encefálico, tabagismo, história familiar de distonia, gravidade do blefaroespasmo, duração do efeito da toxina botulínica e efeitos adversos. Resultados: Foram incluídos 125 pacientes, dos quais 75,2\% eram do sexo feminino. A média de idade do início dos sintomas era 54,3 anos; 89,6\% dos pacientes tiveram início dos sintomas na região ocular e em 39,2\% dos casos houve disseminação para face ou pescoço. Não houve diferenças significativas entre os grupos blefaroespasmo isolado versus blefaroespasmo-plus. 0 tratamento com toxina botulínica proporcionou melhora dos sintomas ( $p=0,01)$ com baixa incidência de efeitos adversos (14\%). Conclusões: Ambos os grupos — blefaroespasmo isolado e blefaroespasmo-plus - apresentaram as mesmas características clínicas, epidemiológicas e resposta terapêutica à toxina botulínica.

Palavras-Chave: blefaroespasmo, toxinas botulínicas.

Blepharospam (BPS) is a focal dystonia characterized by involuntary forceful eye closure and impaired opening of the eyes due to contractions involving the muscles orbicularis occuli, corrugators, procerus and levator palpebrae ${ }^{1}$. BPS can occur isolated or in association with involuntary movements in lower face and neck, called as Meige syndrome, cranial dystonia, segmental craniocervical dystonia or blepharospasm-plus². Furthermore, BPS can also occur in the setting of neurodegenerative diseases, such as Parkinsonism, hereditary ataxias and generalized dystonias.
Among the focal dystonias, BPS and other cranial dystonias usually have a late onset $(\sim 55 \text { years-old })^{3}$ when compared with writer's cramp, cervical dystonia and spasmodic dysphonia ${ }^{4}$. There are few studies concerning the prevalence and incidence rates of this disorder in general population. The prevalence is estimated around 12-133 cases per million ${ }^{5}$. According to a previous study conducted in Minnesota, USA, the annual occurrence of BPS is 1.2 cases per $100.000^{6}$.

\footnotetext{
${ }^{1}$ MD. Movement Disorder Unit, Department of Neurology and Neurosurgery, Universidade Federal de São Paulo (UNIFESP), São Paulo SP, Brazil; ${ }^{2} \mathrm{MD}$, PhD. Movement Disorder Unit, Department of Neurology and Neurosurgery, UNIFESP, São Paulo SP, Brazil.

Correspondence: Camila Catherine Aquino; Rua Napoleão de Barros 715 / térreo / sala 12; 04024-002 São Paulo SP - Brasil; E-mail: camilakt@bol.com.br Support: Dr. Andre C. Felicio is supported by a doctorate fellowship from Fundação de Amparo à Pesquisa do Estado de São Paulo (FAPESP).

Conflict of interest: There is no conflict of interest to declare.

Received 12 January 2012; Received in final form 23 April 2012; Accepted 30 April 2012
} 
Patients with BPS are more likely to experience dystonias in other parts of the body than patients with other focal dystonias ${ }^{7}$. Complaints of dry eye and photophobia are usually reported, but the exact nature of this association remains unestablished ${ }^{5}$. Finally, concerning the genetic pattern and inheritance of BPS, it seems that there is a higher frequency of focal dystonia in relatives, however with a considerable phenotypic variability ${ }^{8}$.

The purpose of this study was to evaluate the demographic and clinical features, including outcomes of botulinum toxin treatment in patients with BPS referred to a Brazilian tertiary care center. Additionally, clinical characteristics of isolated blepharospasm were compared to those of blepharospasm plus other movement disorder.

\section{METHODS}

\section{Patients and data acquisition}

This was a retrospective study, from 1993 to 2010, of 125 consecutive patients with BPS seen at the Movement Disorder Unit of the Universidade Federal de São Paulo (São Paulo, Brazil). During those 17 years, clinical data were recorded in a systematic manner, using a standard clinical protocol. Each case, on the first consultation and subsequent follow-up, was evaluated by an unblinded movement disorder specialist. Incomplete or ambiguously recorded files were not included.

All patients had a detailed neurological examination to rule out other underlying neurological conditions. The criteria for diagnosis of BPS included observation of involuntary bilateral increased blinking with intermittent dystonic eyelid and eyebrow contractions. Patients diagnosed with apraxia of eyelid opening were not included in this study. The severity of BPS was accessed according to the Jankovic rating scale 9 .

\section{Clinical protocol}

The primary aim of this study was to evaluate clinical features and therapeutic outcomes of patients with BPS treated with botulinum toxin injections. Our secondary objective was to compare aforementioned variables between patients with and without associated movement disorders, particularly oromandibular dyskinesia and other focal dystonias.

The following demographic data were recorded: gender, ethnicity (Caucasian, Asian and African Brazilians), age at last appointment and at symptom onset, disease duration, affected site at onset, associated movement disorder, triggering factors, family history of dystonia and previous history of head trauma. History of hypertension, alcohol intake or tobacco use were also recorded.

Informations regarding the oral and surgical treatment for blepharospasm were documented. Two different commercial brands of botulinum toxin (BTX-A) were used throughout the study (Botox ${ }^{\circledR}$ and Dysport ${ }^{\circledR}$ ), according to the product availability at the time of treatment. Standard doses of BTX-A were used on eye region whenever possible (Botox $^{\circledR}$ 60UI and Dysport ${ }^{\circledR}$ 200UI). Additional sites were used if the previous sites had lead to side effects or less effectiveness or the presence of associated movement disorders other than BPS. Treatment response was gauged based on the relief of symptoms between first and last injections.

All subjects signed the informed consent, which explained the treatment and also authorized publication of their data. This study was approved by the ethical committee of Universidade Federal de São Paulo (CEP number 1171/11).

\section{Statistical analysis}

Normality requirements for data distribution were confirmed using Kolmogorov-Smirnov test. Continuous data is presented as mean $( \pm)$ standard deviation, and categorical data as absolute (n) or relative frequency (\%). Comparisons between groups were carried out using Student's $t$-test for continuous variables, whereas Pearson Chi-square test was used for contingency tables. Correlations between independent variables were done using Pearson test. Linear regression analysis was also performed in order to adjust for confounding variables. A corrected p-value of 0.05 was set as the threshold for the statistical significance.

\section{RESULTS}

A total of 125 subjects were included in this statistical analysis. The epidemiological data and clinical features are presented in Table 1.

In relation to previous medical history, head trauma, including mild, had occurred in 13 subjects (10.4\%) before the onset of BPS. High blood pressure was present in $39.2 \%$ individuals, smoking in $20 \%$, and heavy alcohol consumption in $8.8 \%$. Glaucoma was present in only $4(3.2 \%)$ patients. Diagnosis of previous psychiatric disease occurred in $8 \%$ of subjects, predominantly depression; 12 (9.6\%) subjects reported previous use of neuroleptic drug. Two patients were previously diagnosed with Myasthenia Gravis (MG), and the coexistence of both diseases (BPS and MG) is a valid possibility. Brain CT or MRI was conducted in 25 patients (20\%), but no significant abnormality was found. Most patients presented with mild periventricular abnormalities, characteristics of microangiopathy.

Before reporting to our center, 71 (56.8\%) patients had taken oral medications for treatment of blepharospasm without significant improvement. The most frequently used drugs were: benzodiazepines (54.9\%), anticholinergics (33.8\%) and antidepressants (25.3\%). In addition to clinical treatment, ten patients had surgical treatment for BPS, such as blepharoplasty and myectomy. 
From a total of 125 subjects, $113(90.4 \%)$ were treated with BTX-A. The severity of contractions in eyebrow and eyelid, before and after first BTX-A injection, is presented in Figure.

A total of 906 BTX-A injections were performed (mean 8/ patient; range $=2-24$ injections). The difference between severity of BPS in both sites, before and after BTX-A injection was statistically significant, as shown in Figure. The mean duration of BTX-A effect after first injection was 3.1 months. After subsequent injections and adjustment of dosage and site, the duration of effect could be improved to 3.3 months $(\mathrm{p}=0.60)$. Side effects after treatment occurred in $14 \%$ of patients, and the most frequently reported were ptosis, blurred vision, diploplia and felling of "foreign body" in eyes.

The patients were further categorized into two groups the ones with isolated BPS and the ones with BPS plus (BPS+) other movement disorders, such as oral dyskinesia, oromandibular dystonia, spasmodic dysphonia and cervical dystonia - in order to figure out if there were clinical differences between them. The comparison between BPS versus BPS+ groups is presented in Table 2. As showed, no statistically significant differences were found between patients in both groups, except for disease duration before being referred.

\section{DISCUSSION}

BPS is a primary adult-onset dystonia of unknown etiology, but multiple environmental and genetic factors are likely implicated $^{10}$. This study was undertaken to explore different clinical correlation of the disease, which could provide clues

Table 1. Epidemiological data and clinical features of 125 subjects with blepharospasm.

\begin{tabular}{|c|c|c|c|}
\hline Variables & & $n(\%)$ & Mean $( \pm S D)$ \\
\hline Gender & Female & $94(75.2)$ & \\
\hline Age at onset (y) & & & $54.3( \pm 10.4)$ \\
\hline $\begin{array}{l}\text { Duration of symptoms before first } \\
\text { evaluation (mo) }\end{array}$ & & & $128.1( \pm 78.7)$ \\
\hline Time of follow-up (mo) & & & $72( \pm 48)$ \\
\hline Ethnicity & $\begin{array}{l}\text { Caucasian } \\
\text { African } \\
\text { Asian }\end{array}$ & $\begin{array}{l}85(68) \\
8(6.4) \\
9(7.2)\end{array}$ & \\
\hline Distribution of dystonia at onset & $\begin{array}{l}\text { Eye } \\
\text { Oromandibular } \\
\text { Others (i.e.: cervical, vocal cords) }\end{array}$ & $\begin{array}{l}112(89.6) \\
11(8.8) \\
3(2.4)\end{array}$ & \\
\hline Movement disorder in follow-up & $\begin{array}{l}\text { BPS isolated } \\
\text { BPS plus (Meige, craniocervical dystonia) } \\
\text { Other (parkinsonism, tremor) }\end{array}$ & $\begin{array}{l}65(52) \\
49(39.2) \\
8(6.4)\end{array}$ & \\
\hline Main triggering factors & $\begin{array}{l}\text { Stress, anxiety } \\
\text { Photophobia, light, clarity }\end{array}$ & $\begin{array}{l}34(27.2) \\
13(10.4)\end{array}$ & \\
\hline Family history of dystonia & & $11(8.8)$ & \\
\hline
\end{tabular}

n: number of patients; y: years; mo: in months; SD: standard deviation.

Table 2. Comparison between blepharospams groups associated or not with other movement disorder.

\begin{tabular}{|c|c|c|c|}
\hline Comparison of groups & $\begin{array}{c}\text { BPS } \\
(n=65)\end{array}$ & $\begin{array}{l}\text { BPS+ } \\
(n=57)\end{array}$ & p-value \\
\hline Gender, female/male,ratio & $2.82(48 / 17)$ & $3.2(46 / 14)$ & $0.13 ; \mathrm{NS}$ \\
\hline $\begin{array}{l}\text { Ethnicity } \\
\text { Caucasian } \\
\text { African } \\
\text { Asian }\end{array}$ & $\begin{array}{l}49(75.3 \%) \\
3(4.16 \%) \\
2(3.0 \%)\end{array}$ & $\begin{array}{l}36(63.15 \%) \\
5(8.7 \%) \\
7(12.2 \%)\end{array}$ & $0.17 ; \mathrm{NS}$ \\
\hline Age symptom onset (y) & $54.1 \pm 11$ & $54.0 \pm 10.3$ & $0.90 ; N S$ \\
\hline Disease duration before first visit (mo) & $143 \pm 82.8$ & $97 \pm 63$ & $<0.01 ; \mathrm{S}$ \\
\hline $\begin{array}{l}\text { Distribution of dystonia at onset } \\
\text { Eyes } \\
\text { Oral dyskinesia/dystonia } \\
\text { Larynx }\end{array}$ & $65(100 \%)$ & $\begin{array}{l}52(91.2 \%) \\
3(5.2 \%) \\
1(1.7 \%)\end{array}$ & \\
\hline Family history of dystonia & 2 & 3 & $0.50 ; N S$ \\
\hline Severity eyelid contractions before BTX-A* & $3.19 \pm 0.97$ & $3.08 \pm 0.93$ & $0.90 ; N S$ \\
\hline Severity eyelid contractions after first BTX-A* & $1.51 \pm 1.23$ & $0.96 \pm 0.91$ & $0.13 ;$ NS \\
\hline Duration of relief after first injection & $3.37 \pm 3.75$ & $2.82 \pm 1.28$ & $0.69 ; N S$ \\
\hline
\end{tabular}

BPS: blepharospams groups; BPS+: blepharospams groups associated with other movement disorder; n: number of patients; y: years; mo: months; NS: without statistical significance; BTX-A: botulinum toxin. *See legend to Fig. 
as to the etiopathogenesis. The discussion that follows is divided into two sets; firstly, we discuss BPS demographic and clinical features, and then its therapeutic outcomes comparing to literature data.

\section{Demographic and clinical features}

Our patients presented the same average age, sex and ethnicity distribution as reported elsewhere ${ }^{11,12}$. The majority of patients had onset in the eye region, and almost $40 \%$ developed spread during the follow up. This is an interesting observation since the mean time of follow up was about six years, and some patients were followed during more than ten years. When asked about triggering factors, most patients reported stress and anxiety, followed by photophobia and light to be more relevant. Moreover, few subjects reported previous ocular disease, such as glaucoma. A recently published well designed study found an evidence of ocular disease such as dry eye, blepharitis and keratoconjuctivitis in 50 of 140 patients with $\mathrm{BPS}^{10}$.

Previous studies have showed non-significant associations between alcohol use, hypertension and minor head trauma (without loss of consciousness) with $\mathrm{BPS}^{13}$. On the other hand, head trauma with loss of consciousness ${ }^{13}$ and as a protective caffeine intake ${ }^{14}$, have been suggested as a risk factor and as a protective factor, respectively. The lack of a control group in our study precluded confirmation of those associations.

Concerning the family history of dystonia, we found a positive history reported by $8.8 \%$ of patients. We have to highlight that this data was acquired through patient report and that their family members were not examined in our center. Positive family history in previously published articles ranged from 7 to $32 \%$, according to distinct methodology and population studied ${ }^{8,12,13,15}$.
When patients with isolated BPS were compared with patients with BPS+, such as Meige syndrome, craniocervical dystonia and laryngeal dystonia, no significant differences were found, showing that those disorders are probably spectrum of the same disorder. In BPS+ group, BPS was the first presentation in $91.2 \%$ and subsequently spread to lower face, neck or vocal cords. BPS has the highest likelihood for further spread, occurring in about $33.3 \%$, followed by dystonia of upper extremities, torticollis and laryngeal dystonia ${ }^{16}$.

\section{Therapeutic outcomes}

In our series, 113 out of 125 patients were treated with BTX-A. As showed in Figure, the severity of BPS improved either in the eyebrow or eyelid. There were significant differences in BPS severity in each site before and after BTX. This response was evaluated in first injection, and, even thought we did not analyze the response in all subsequent injections, most of patients presented the same therapeutic effect during follow up. According to a recent systematic review on botulinum toxin for BPS, although BTX is a highly safe treatment for BPS, information about best regimen treatment, injections techniques and formulations are not clear ${ }^{17}$.

In this study, we did not find significant differences with regard to the duration of symptom relief after BTX injection. The mean time of follow up was about 72 months, but some patients were seen throughout 10 years, and we did not find any case with secondary resistance to BTX-A.

In a previous Brazilian study, 30 patients with BPS under BTX-A treatment were evaluated and about $93 \%$ of them had symptom improvement, with maintenance of relief duration in the time of follow up and low incidence of side effect ${ }^{18}$. On

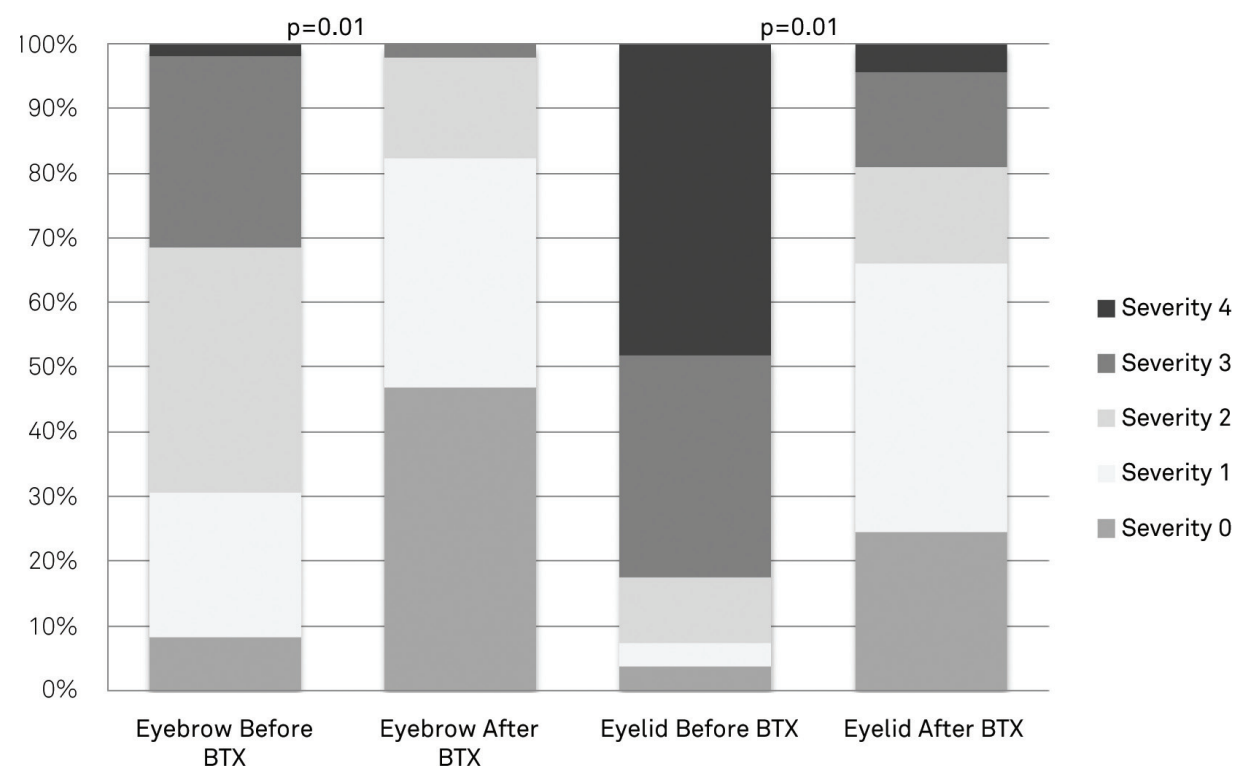

*Severity 0: no visible contraction. Severity 1: increased blinking present with external stimuli. Severity 2: mild but spontaneous fluttering, definitely noticeable, possibly embarrassing, but not functionally disabling. Severity 3: moderate, very noticeable spasm, mildly incapacitating. Severity 4 : severe, incapacitating spasm.

Figure. Severity of blepharospasm before and after first botulinum toxin injection. 
the other hand, a Canadian study on the duration of longterm symptom relief in patients with either BPS or Hemifacial Spasm (HFS) found that the mean duration of relief in BPS patients after early injections was 13.5 weeks and after later injections was 11.4 weeks, with statistical significance. That difference was not found in HFS ${ }^{19}$.

Side effects occurred in $14 \%$ of patients in our sample, and most of them were mild and transient, agreeing with a systematic review that pointed to the safety of this therapeutic approach ${ }^{17}$.

Finally, we did not observe any differences in symptom relief, duration or occurrence of side effects when we compared patients with isolated BPS and BPS plus other movement disorder, showing that they not only share the same clinical and demographic features but also therapeutic outcomes.
This study has several limitations, such as referral bias and its retrospective nature. Another problem was related to Brazil's complex ethnic heterogeneity, hence it was difficult to separate patients clearly into subgroups according to ethnicity. Additionally, it is worth mentioning that this study was conducted in a community hospital, and, during the follow up, patients were treated with two different brands of BTX-A, as aforementioned. Because of that, we could not compare long term relief with distinct brands.

In this retrospective case-record study on a large population of BPS patients, we found that clinical and therapeutic outcomes in patients with BPS or BPS plus are similar. Accordingly, this Brazilian sample of patients taken together also has similar features as compared to literature data.

\section{References}

1. Nicoletti AGB, Aoki L, Nahas TR, Matayoshi S. Blefaroespasmo essencial: revisão da literatura. Arq Bras Oftalmol 2010;73:469-473.

2. LeDoux MS. Meige syndrome: what's in a name? Parkinsonism Relat Disord 2009;15:483-489

3. Anderson RL, Patel BC, Holds JB, Jordan DR. Blepharospasm: past, present, and future. Ophthal Plast Reconstr Surg 1998;14:305-317.

4. O'Riordan S, Raymond D, Lynch T, et al. Age at onset as a factor in determining the phenotype of primary torsion dystonia. Neurology 2004;63:1423-1426.

5. Hallett M, Evinger C, Jankovic J, Stacy M. Update on blepharospasm: report from the BEBRF International Workshop. Neurology 2008;71:1275-1282.

6. Bradley EA, Hodge DO, Bartley GB. Benign essential blepharospasm among residents of Olmsted County, Minnesota, 1976 to 1995: an epidemiologic study. Ophthal Plast Reconstr Surg 2003;19:177-181.

7. Weiss EM, Hershey T, Karimi M, et al. Relative risk of spread of symptoms among the focal onset primary dystonias. Mov Disord 2006;21:1175-1181.

8. Defazio G, Martino D, Aniello MS, et al. A family study on primary blepharospasm. J Neurol Neurosurg Psychiatry 2006;77:252-254.

9. Jankovic J, Kenney C, Grafe S, Goertelmeyer R, Comes G. Relationship between various clinical outcome assessments in patients with blepharospasm. Mov Disord 2009;24:407-413.

10. Defazio G, Abbruzzese G, Aniello MS, et al. Environmental risk factors and clinical phenotype in familial and sporadic primary blepharospasm. Neurology 2011;77:631-637.
11. Defazio G, Livrea P. Epidemiology of primary blepharospasm. Mov Disord 2002;17:7-12.

12. Peckham EL, Lopez G, Shamim EA, et al. Clinical features of patients with blepharospasm: a report of 240 patients. Eur $\mathrm{J} \mathrm{Neurol}$ 2011;18:382-386.

13. Defazio G, Berardelli A, Abbruzzese G, et al. Possible risk factors for primary adult onset dystonia: a case-control investigation by the Italian Movement Disorders Study Group. J Neurol Neurosurg Psychiatry 1998;64:25-32.

14. Defazio G, Martino D, Abbruzzese G, et al. Influence of coffee drinking and cigarette smoking on the risk of primary late onset blepharospasm: evidence from a multicentre case control study. J Neurol Neurosurg Psychiatry 2007;78:877-879.

15. Jankovic J, Ford J. Blepharospasm and orofacial-cervical dystonia: clinical and pharmacological findings in 100 patients. Ann Neurol 1983;13:402-411.

16. Svetel M, Pekmezović T, Jović J, et al. Spread of primary dystonia in relation to initially affected region. J Neurol 2007;254:879-883.

17. Costa J, Espírito-Santo C, Borges A, et al. Botulinum toxin type A therapy for blepharospasm. Cochrane Database Syst Rev 2005;CD004900.

18. Silveira-Moriyama L, Gonçalves LR, Chien HF, Barbosa ER. Botulinum toxin a in the treatment of blepharospasm: a 10-year experience. Arq Neuropsiquiatr 2005;63:221-224.

19. Gill HS, KraftSP.Long-term efficacy of botulinum a toxin for blepharospasm and hemifacial spasm. Can J Neurol Sci 2010;37:631-636. 